\title{
HEART RATE TURBULENCE AS A MORTALITY PREDICTOR IN LONG-TERM STUDY IN PATIENTS WITH CORONARY HEART DISEASE
}

Gareeva D. ${ }^{1}$, Zagidullin N. ${ }^{1}$, Lakman I. ${ }^{2}$, Islamova R. ${ }^{2}$, Zagidullin Sh. ${ }^{1}$

Pathological heart rate turbulence (HRT) after premature ventricular complexes (PVCs) in patients with coronary heart disease (CHD) and myocardial infarction (MI) may predict higher mortality rate.

Aim. To estimate the predictive power HRT in 5 year observational study in patients with CHD.

Material and methods. 173 patients with $\mathrm{CHD}$ and in whom HRT was possible to record, were analyzed from 2010-2011 until 2015 with survival rate and turbulence slope (TS) and turbulence onset (TO) estimation.

Results. Pathological TO showed no correlation with survival rate $(p>0,05)$ but pathological TS in 5 years period $(p=0,00026)$ correlated with survival rate with post-MI patients. Moreover, it had a predictive power also with non-MI patients $(p=0,0032)$. The survival (Kaplan-Mayer) curves between normal and pathological TS started to divide from the 36 months of observation. Presence of nTS in post MI patients increased mortality rate in 5,14 times $(p=0,00002)$ and in non-MI - in 4,99 times $(p=0,00002)$.

Conclusions. HRT slope parameter showed to be highly effective in mortality risk prediction in patients with $\mathrm{CHD}$.
Key words: heart turbulence rate, total mortality, myocardial infarction.

${ }^{1}$ Bashkir State Medical University, Ufa; ${ }^{2}$ Ufa State Aviation Technical University, Ufa, Russia.

Corresponding author. Gareeva Diana, clinical resident of Department of Internal Medicine, Bashkir State Medical University, Ufa; assistant in Cardiology Department, city hospital N21, Ufa. Work address: 450000, Ufa, Lenin str, 3. Tel.: +79191407149. Email: gareevadf@gmail.com.

CHD - coronary heart disease, ECG - electrocardiography, HRT - heart rate turbulence, $\mathrm{MI}$ - myocardial infarction, PVCs - premature ventricular complexes, TO - turbulence onset, TS - turbulence slope.

Received January 31, 2016.

Revision received February 04, 2016.

Accepted February 11, 2016

Russ J Cardiol 2016, 4 (132), Engl.: 190-194

http://dx.doi.org/10.15829/1560-4071-2016-4-eng-190-194

\section{ТУРБУЛЕНТНОСТЬ СЕРДЕЧНОГО РИТМА КАК ПРЕДИКТОР СМЕРТНОСТИ В ДОЛГОСРОЧНОМ ИССЛЕДОВАНИИ У ПАЦИЕНТОВ С ИШЕМИЧЕСКОЙ БОЛЕЗНЬЮ СЕРДЦА}

Gareeva D. ${ }^{1}$, Zagidullin N. ${ }^{1}$, Lakman I. ${ }^{2}$, Islamova R. ${ }^{2}$, Zagidullin Sh.

Патологическая турбулентность сердечного ритма (HRT) после преждевременных желудочковых комплексов (PVCs) у больных ишемической болезнью сердца (ИБС) и инфарктом миокарда (ИМ) может прогнозировать более высокую смертность.

Цель. Для оценки предсказательной силы HRT у 5-летнего обсервационного исследования у пациентов с ИБС.

Материал и методы. 173 пациентов с ИБС, у которых НRT удалось записать, были проанализированы с 2010-2011 до 2015 года на выживаемость и наклон турбулентности (TS) и начало турбулентности (TO).

Результаты. Патологические ТО не показали никакой корреляции с коэффициентом выживаемости ( $p>0,05)$, но патологические TS в течение 5 лет ( $p=0,00026)$ коррелируют с частотой выживания у пост-ИМ пациентов Кроме того, они имеют предсказательную силу также у не-ИМ пациентов $(p=0,0032)$. Кривые выживаемости (Каплан-Майер) между нормальной

In the last decades, cardiovascular morbidity and mortality from diseases are on the leading positions in the Russian Federation. According to the World Health Organization, more than 16.5 million people a year die from cardiovascular diseases, including CHD - more than 7 million, accounting for 29.3 and $12.6 \%$ of the total mortality accordingly. Mortality from myocardial infarction (MI) in the post-MI period remains also high so is the incidence of sudden cardiac death [1], which determines the need of diagnostic and preventive measures. New parameter "heart rate turbulence" (HRT) which reflects the short-term regression of the heart rhythm with subsequent acceleration after premature ventricular construction (PVCs) was scientifically proved in 1999 [2]. It was и патологической TS начали делить от 36 месяцев наблюдения. nTS у больных ИМ увеличилось смертность в 5,14 раза ( $p=0,00002$ ), а у не-ИМ - в 4,99 раза ( $p=0,00002)$.

Заключение. Параметр HRT показал высокую эффективность в прогнозировании риска смертности у пациентов с ИБС.

Российский кардиологический журнал 2016, 4 (132), Англ.: 190-194 http://dx.doi.org/10.15829/1560-4071-2016-4-eng-190-194

Ключевые слова: турбулентность сердечного ритма, общая смертность, инфаркт миокарда

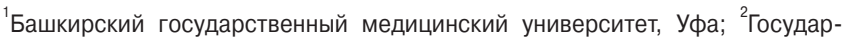
ственный авиационно-технический институт, Уфа, Россия.

shown that in patients with postMI period the pathological is observed, which reflects high cardiovascular risk in the patients. [3, 4]. However, it is still not clear whether the HRT reflects the high cardiovascular risk in patients without MI in the past.

The aim of the study was to improve the diagnostics of coronary heart disease in patients with HRT as a cardiovascular risk factor

\section{Material and methods}

More than 3.00024h electrocardiographic (ECG) record in patients with CHD were analyzed, that were treated in the department of cardiology in 2010-2011 in clinical hospital №21 Ufa, and 205 patients meeting the criteria for inclusion 


\section{Inclusion and exclusion criteria in the study}

\author{
Inclusion criteria \\ Established diagnosis of coronary artery disease in accordance with the European \\ Society of Cardiology criteria (2008); \\ Presence of ventricular premature construction (PVCs) according 24h ECG meet \\ the following criteria [5]: \\ $\cdot$ RR intervals $<2000$ and $>300 \mathrm{~ms}$, \\ -PVCs with difference between the preceding sinus intervals $<200 \mathrm{~ms}$ \\ - PVCs with difference $<20 \%$ of the average of 5 consecutive sinus intervals \\ - PVCs prematurity index $>20 \%$ and postectopic interval longer than the average \\ RR on $20 \%$ or more \\ Patients should receive permanent anti-anginal therapy at the time of the study; \\ Absence of exclusion criteria; \\ Age $<75$ years $[5]$
}

were selected for the experimental group. Inclusion and exclusion criteria are presented in Table 1.

The primary endpoint in the study was overall mortality during the 4-5 year follow-up after the initial determination of HRT.

Heart rate turbulence can be determined by standard 24-hour ECG monitoring (Figure 1) [3, 6]. Two phases of HRT, the early sinus rate acceleration and late deceleration, are quantified by 2 parameters termed as turbulence onset (TO) and turbulence slope (TS). TO is calculated as: $\mathrm{TO}=\left(\mathrm{RR}_{1}+\mathrm{RR}_{2}\right)-\left(\mathrm{RR}_{-2}+\mathrm{RR}_{-1}\right)\left(\mathrm{RR}_{-2}+\mathrm{RR}_{-1}\right) \times 100$, where $R_{-2}$ and $R_{-1}$ are the $2 R_{-} R^{-1}$ intervals immediately preceding the PVCs coupling interval, and RR1 and RR2 are $2 \mathrm{R}-\mathrm{R}$ intervals immediately following the compensatory pause. TS is defined as the maximum positive regression slope assessed over any 5 consecutive sinus rhythm $\mathrm{R}-\mathrm{R}$ intervals within the first 15 sinus rhythm R-R intervals after the PVCs. Normally, there is an acceleration of sinus rhythm after PVCs, which is reflected in the negative TO value with a subsequent slowdown with positive TS.

Patients with HRT are usually stratified into three categories: 1) HRT category 0 means TO and TS are normal (nTO and nTS accordingly); 2) HRT category 1 means 1 of TO or TS is abnormal (pTO and aTS accordingly); and 3) HRT category 2 means both TO and TS are abnormal.

24-hour ECG monitoring was performed by"Kardiotekhnika-04-8 (M)" ("INKART", St. Petersburg) 24h monitoring with hardware, allows to record and analyze forms of ventricular complexes in accordance with HRT analysis. HRT analysis was performed in 2010-2011 in time of patients' hospitalization, and later in 2011-2015 the follow up telephone contacts was performed annually to monitor the primary endpoint.

Group analysis is presented in mean values (M) and standard deviation $(\mathrm{m})$. Statistical analysis was performed using survival tables and Kaplan-Meier survival regression models, particularly the proportional hazards model (Cox model). Model coefficients estimation was obtained by maximum likelihood. Statistical analysis was performed using "Statistica 10.0"program (module "Survival analysis").

\section{Exclusion criteria}

Pacemaker installed;

Chronic heart failure NYHA II-IV;

Permanent / persistent form of atrial fibrillation and flutter;

Atria-ventricular block of 2-3 degree;

Sick sinus syndrome;

The complete bundle-branch block;

Heart rate $>80$ beats/min;

Severe valvular heart disease, cardiomyopathy;

Renal and hepatic failure;

Alcohol abuse, drug addiction, the pathology of the central nervous system (cancer, metabolic, infectious, mental and others disease, brain injury, depression, epilepsy, dementia, transient ischemic attack, cerebrovascular accident in the acute stage)

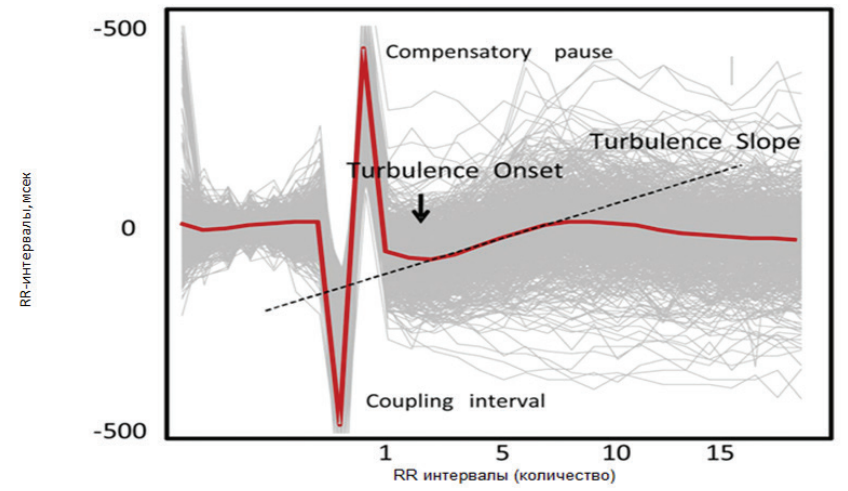

Figure 1. Estimation of HRT by 24-hour ECG:HRT smoothed curve (red curve) after averaging the signal from single tachograms (gray lines). The arrow indicates the start of turbulence (turbulence onset) and turbulence slope (turbulence slope)

Table 2

\section{Characteristics of the investigated contingent}

\begin{tabular}{|l|l|}
\hline Parameters & Values, $\mathbf{n}=\mathbf{1 7 3}$ \\
\hline Age, years & $67,06 \pm 0,79$ \\
\hline Gender (m/f), & $106 / 67$ \\
\hline Height, cm & $169,6 \pm 1,8$ \\
\hline Weight, kg & $84,6 \pm 3,0$ \\
\hline BMl, kg/m ${ }^{2}$ & $29,4 \pm 0,89$ \\
\hline Coronary / coronary artery bypass grafting/ stenting, $\mathrm{n}$ & 23 \\
\hline History of myocardial infarction, $\mathrm{n}$ & 137 \\
\hline Arterial hypertension, $\mathrm{n}$ & 130 \\
\hline Stroke, $\mathrm{n}$ & 10 \\
\hline Diabetes mellitus, $\mathrm{n}$ & 21 \\
\hline Cholesterol, mmol/l & $4,78 \pm 0,08$ \\
\hline Ejection fraction, \% & $54,0 \pm 1,06$ \\
\hline
\end{tabular}

\section{Results}

The main part of patients with HRT was defined by ECG 24h records analysis in 2010-2011. The survival status was estimated by follow up telephone contact and by medical events registration in state medical statistical program "Promed" providing survival data during next 5 years. 32 patients retired from the study because of contact 
Table 3 lost and 173 patients remained available for analysis and

\section{Characteristics of heart rate turbulence}

\begin{tabular}{|l|l|}
\hline Parameters & HRT $(\mathbf{n}=\mathbf{1 7 3})$ \\
\hline PVCs number/day & $176,9 \pm 18,8$ \\
\hline Heart rate, beats/min & $68,1 \pm 0,57$ \\
\hline TO, \% & $-0,96 \pm 0,25$ \\
\hline TS, ms/RR & $6,14 \pm 0,38$ \\
\hline
\end{tabular}

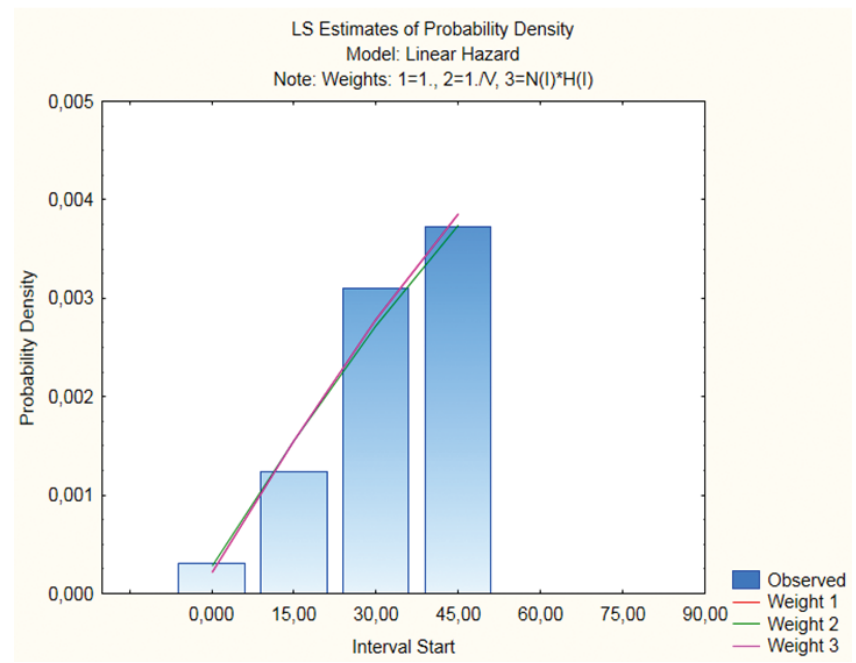

Figure 2. Mortality risk over 5 years period in patients with aTS ( $X$ axis - months, and Y-mortality risk).

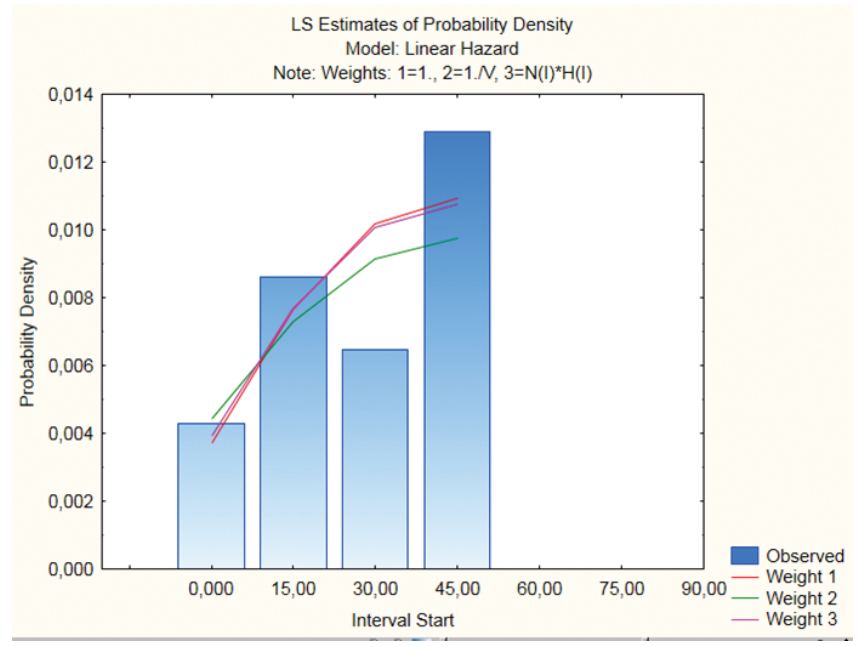

Figure 3. Mortality risk in 5 years in patients with aTS ( $x$ axis - months, y axis mortality risk). long-term results. Table 2 shows the characteristics of patients in the study. The average age of the patients was $67.06 \pm 0.79$ years, 67 women, and 106 men. Patient's height was $169,9 \pm 1,8 \mathrm{~cm}$, weight $-84,6 \pm 3,0 \mathrm{~kg}$, body mass index (BMI) $-29,4 \pm 0,89 \mathrm{~kg} / \mathrm{m}^{2}$. The number of post-MI patients was 137 , patients with coronary angiography / coronary stenting / or coronary artery bypass grafting -23 , after stroke -10 , with arterial hypertension -130 , diabetes mellitus -21 . Some other cardiovascular parameters: blood cholesterol $-4,78 \pm 0,08 \mathrm{mmol} / \mathrm{l}$, and left ventricular ejection fraction $-54,0 \pm 1,06 \%$ were also identified.

In Table 3 the electrophysiological characteristics of VPC and HRT are presented.

The number of PVCs was 176,9 $\pm 18,8 /$ day, and average heart rate $-68,1 \pm 0,57$ beats/min. HRT parameter TO was $0,96 \pm 0,25 \%$, and TS $-6,14 \pm 0,38 \mathrm{~ms} / \mathrm{RR}$.

As described above, we investigated 2 HRT parameters, which have predictive power for patients prognosis: TS and TO $[3,6]$. TO was not significant for survival models, and we analyzed relationship of mortality and HRT in survival analysis with TS parameter only. Abnormal TS (aTS) is $\leq 2,5 \mathrm{~ms} / \mathrm{RR}$, and normal (nTS) $>2,5[3,6]$. Table 4 shows the mortality in the group based on TS.

Survival in the 5-year interval depending on heart rate turbulence

In first phase, the overall mortality over the 5-year period was evaluated. For calculation of mortality and survival graphs for the 5 -year period the 2 groups of patients: with nTS and aTS were compared with each other.

The mortality risk in patients with HRT. Figure 2 presents mortality risk assessment within 5 years in patients with CHD and nTS. The graph was constructed by subtracting of given interval from the value of the survival function values of the next interval and then dividing by the "width" of the corresponding interval.

Mortality risk was minimal for the first 20 months after the initial HRT, it gradually increased later and the achieved the maximal probability in 30-45 months range.

Mortality risk in patients with aTS. In patients with CHD and aTS The following mathematical model of mortality during the observed period was used:

Table 4 Mortality in long-term period in patients with HRT

\begin{tabular}{|l|l|l|l|l|l|l|}
\hline Parameters & $\mathbf{n}$ & $\mathbf{1 2}$ months & $\mathbf{2 4}$ months & $\mathbf{3 6}$ months & $\mathbf{4 8}$ months \\
\hline nTS & 135 & 2 & 6 & 8 & 5 \\
\hline aTS & 38 & 8 & 5 & 1 & 6 \\
\hline All & 173 & 10 & 11 & 9 & 1 \\
\hline
\end{tabular}




$$
\begin{aligned}
& \lambda_{\mathrm{i}}\left(t \mid x_{\mathrm{i}}\right)=\lambda_{0}(\mathrm{t}) * \mathrm{e}^{1.61^{*} T S_{-} D .}, \\
& \text { where } T S_{-} D=\left\{\begin{array}{l}
1, \text { if } \mathrm{ts} \leq 2.4 \\
0, \text { if } \mathrm{ts}>2.4)
\end{array}\right.
\end{aligned}
$$

Testing of the model showed its significance: an estimated value of $\chi^{\wedge} 2$ - statistics 16,8 , which exceeded the tabular value of 5,992 , determined in 2 degrees of freedom and a significance level of $p<0,05$. Cox model parameters was statistically significant: presence of aTS influenced mortality risk over five year period - the presence of aTS in CHD patients compared to nTS enhanced mortality likelihood in 4,99 times. Considering the confidence level of $95 \%$ the mortality risk in the five-year period in compare with nTS increased into 2,37-10,51 times.

Figure 3 shows graph of mortality in 5-year time interval for patients with aTS. The function was constructed similarly as for patients with nTS (see above). In patients with aTS the mortality risk was minimal during the first 15 months after the start of monitoring, upraised from 20 to 30 months, and achieved maximum between 45 and 60 months.

Figure 4 shows both nTS and aTS mortality curves. The divergence of the curves starts from 24 months, and intensifies with years.

\section{Analysis of mortality depending on TS and myocardial infarction}

According to most of published data, pathological HRT has predictive power only in post-IM patients [7-9], so we compared Kaplan-Meier survival curves based on MI in the past and on nTS/aTS (Table 5).

While analyzing the data for five years 2 survival models depending on TS parameters and presence of MI in the past were created. In the first model, we compared survival curves in post-MI patients and nTS/aTS, and the second in non-MI.

Survival curves in post-MI patients and nTS/aTS. For a more detailed analysis of difference in survival rates post-MI patients with nTS $(n=106)$ and aTS $(n=30)$ are investigated. Based on Kaplan-Meier survival graph (Figure 5), according to Gehan's-Wilcoxon criteria, the survival rate in post-MI patients with nTS was considerably higher than with aTS $(\mathrm{p}=0,00026)$.

The survival rate in non MI patients with nTS/aTS. In this model, the compare of survival rates in non-MI patients with nTS $(n=30)$ and aTS $(n=7)$ was performed. In Kaplan-Meier survival graphs (Figure 6) the survival rate of patients without MI and with nTS were significantly higher than with aTS $(\mathrm{p}=0.00318)$.

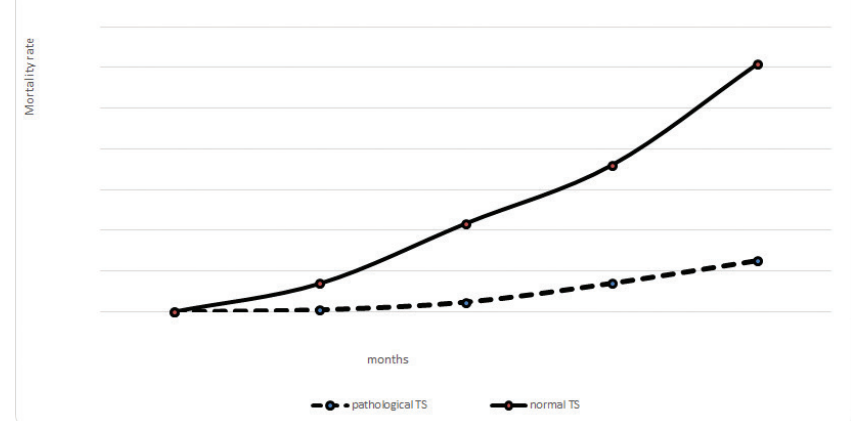

Figure 4. Mortality within 5 years in patients with $\mathrm{CHD}$ with $\mathrm{nTS} / \mathrm{aTS}$.

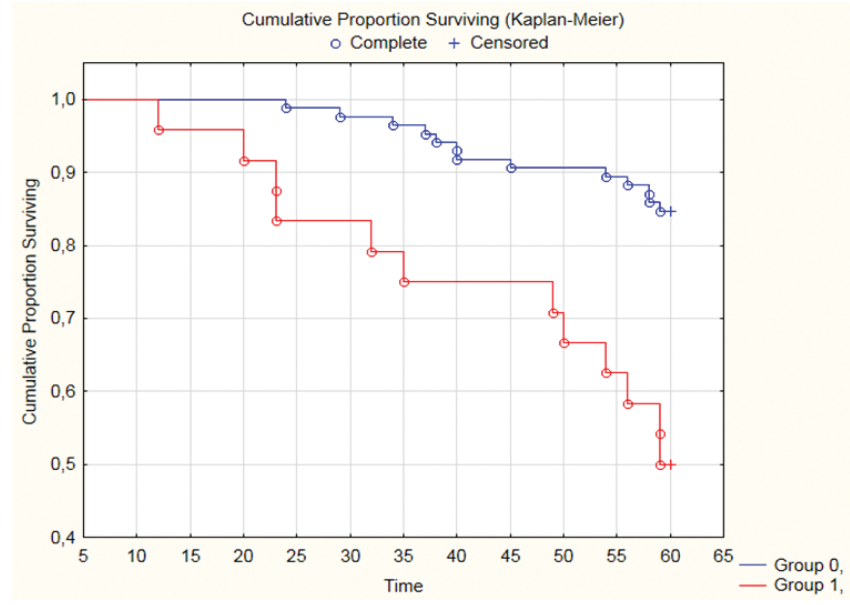

Figure 5. 5-year survival Kaplan-Mayer curves in post-Ml patients with nTS (blue) and aTS (red).

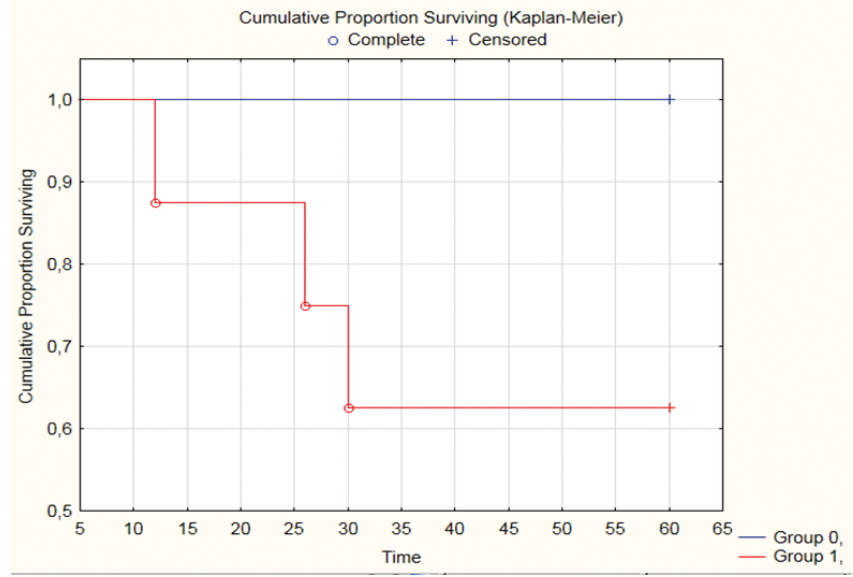

Figure 6. Survival graphs in non-Ml patients with nTS (blue) and aTS (red).

Table 5

Mortality rate in patients with CHD and HRT

\begin{tabular}{|l|l|l|l|l|l|l|}
\hline Models & $\mathbf{n}$ & $\mathbf{1 2}$ month & $\mathbf{2 4}$ month & $\mathbf{3 6}$ month & $\mathbf{4 8}$ month & $\mathbf{6 0}$ month \\
\hline IM+nTS & 106 & 0 & 6 & 5 & 5 & 4 \\
\hline IM+aTS & 30 & 8 & 5 & 0 & 5 & 1 \\
\hline nolM+nTS & 30 & 2 & 0 & 2 & 0 & 0 \\
\hline nolM+aTS & 7 & 0 & 0 & 1 & 2 & 0 \\
\hline
\end{tabular}




\section{Discussion}

Populational cardiology based mostly on the success of evidence-based medicine. One of the modern achievements are cardiovascular risk scales, for example in patients with PVC in whom it is possible to estimate HRT [3]. We analyzed 173 patients with CHD, in whom was possible to estimate HRT. The 5-year observation was done to determine the primary end point - general mortality. Two HRT parameters were previously shown to have predictive power: TS and TO [3]. In our study TO didn't show impact on long-term survival of patients, only TS was analyzed. In the first step, we analyzed the 5-year survival rate depending on normal and abnormal TS (nTS/aTS). Presence of aTS in patients with CHD increased the death likelihood for 5.1 times in compare with nTS. The maximal mortality risk after HRT record was in 45-60 weeks range, and the divergence of survival curves started from the second year. On the second step, we compared the survival curves of patients with previous MI and with nTS and aTS. Existence of aTS significantly increased mortality in compare with nTS $(\mathrm{p}=0,00026)$. The role of HRT, a significant risk factor in patients with CHD with previous MI, has been proved in several large-scale retrospective and prospective studies $[3,8,9]$. All HRT studies, except of CAST (Cardiac Arrhythmia Suppression Trial), used the same reference values of TO and TS parameters, that is, $0 \%$, and 2.5

\section{References}

1. Moss AJ, Hall WJ, Cannom DS, et al. Improved survival with an implanted defibrillator in patients with coronary disease at high risk for ventricular arrhythmia. Multicenter Automatic Defibrillator Implantation Trial Investigators. N Engl J Med. 2006;335:1933-40.

2. Lanza GA, Sgueglia GA, Angeloni G, et al. Prognostic value of heart rate turbulence and its relation to inflammation in patients with unstable angina pectoris. Am J Cardiol. 2009; 15:103(8):1066-72.

3. Bauer A, Malik M, Schmidt G, et al. Heart rate turbulence: standards of measurement, physiological interpretation, and clinical use: International Society for Holter and Noninvasive Electrophysiology Consensus. J Am Coll Cardiol. 2008; 52: 1353-65.

4. Bauer A, Malik M, Barthel P, et al. Turbulence dynamics: an independent predictor of late mortality after acute myocardial infarction. Int J Cardiol. 2006;107:42-7.

5. Tsvetnikova AA, Yuarngart ER, Parmon EV, et al. Heart rate turbulence: methodological aspects. - AS Saint-Petersburg: INKART 2008, 32c.

6. Gareeva DF, Zagidullin $\mathrm{BI}$, Nagaev IA, et al. Heart rate turbulence as a predictor of the risk of cardiovascular death. Practical medicine. 2012; 6: 39-43.

7. Zuern CS, Barthel P, Bauer A. Heart rate turbulence as risk-predictor after myocardial infarction. Front Physiol. 2011 Dec 12;2:99. doi:10.3389/fphys.2011.00099. eCollection 2011. PubMed PMID: 22180744; PubMed Central PMCID: PMC3238051.
ms/RR intervals, accordingly. In patients with HRT category 2 (i.e. with aTO and aTS) mortality risk increased by 4,4-11,3 times within 2 years compared to patients with normal HRT ( 0 category).

Then, we compared survival curves with nTS and aTS in patients without MI. Parameter aTS also raised the mortality $(p=0.00318)$ but surely less then in post-MI patients. Prognostic role of HRT in CHD patients without a history of MI was not properly studied [11, 12] and, based on presented data, aTS may predict mortality risk in patients without MI in the past [12,13].

\section{Conclusion}

It was proved that in patients with CHD and PVCs, abnormal TS parameter of HRT is highly predictive in determining the general mortality over a 5-year period, where the divergence of the survival curves starts from the second year of monitoring. Unlike other observations, the differences between survival graphs was shown not only for patients with previous MI but also without it.

Acknowledgments. Study was supported by Russian Humanitarian Foundation Grant 15-36-01255/15 and grant UMNIK of Foundation for Assistance of Small Innovative Enterprises in Science and Technology (2013, Gareeva D).

8. Barthel P, Schneider R, Bauer A, et al. Risk stratification after acute myocardial infarction by heart rate turbulence. Circulation. 2003;108:1221-6.

9. Exner DV, Kavanagh KM, Slawnych MP, et al., on behalf of REFINE Investigators. Noninvasive risk assessment early after a myocardial infarction the REFINE study. J Am CollCardiol. 2007;50:2275-84.

10. Stein PK, Deedwania P. Usefulness of abnormal heart rate turbulence to predict cardiovascular mortality in high-risk patients with acute myocardial infarction and left ventricular dysfunction (from the EPHESUS study). Am J Cardiol. 2009;103:14951499.

11. Sestito A, Valsecchi S, Infusino F, et al. Differences in heart rate turbulence between patients with coronary artery disease and patients with ventricular arrhythmias but structurally normal hearts. Am J Cardiol. 2004;93:1114-8.

12. Bauer $A, B$ arthel $P$, Schneider R. et al. Improved stratification of autonomic regulation for risk prediction in post-infarction patients with preserved left ventricular function (ISARRisk). Eur Heart J. 2009;30:576-83.

13. Bauer A, Kantelhardt JW, Barthel P. et al. (2006a). Deceleration capacity of heart rate as a predictor of mortality after myocardial infarction: cohort study. Lancet. 2006;367:1674-81. 